\title{
ESTUDOS EPIDEMIOLOGICOS ENTRE GRUPOS INDÍGENAS DE RONDÓNIA I - PIODERMITES E PORTADORES INAPARENTES DE STAPHYLOCOCCUS sp. NA BOCA E NARIZ ENTRE OS SURUÍ E KARITIANA
}

Carlos E. A. COIMBRA JR. (1), Ricardo Ventura SANTOS (2) e Ronan TANUS (2)

\section{RES U M O}

Foram realizadas culturas bacteriológicas a partir de material colhido na boca e nariz entre 38 pacientes indígenas Suruí e 58 Karitiana, no Estado de Rondônia. Entre os Suruí, foi isolado S. aureus em $10(26,3 \%)$ indivíduos e S. epidermidis em $25(65,8 \%)$. Na população Karitiana, S. aureus foi isolado em 21 $(36,2 \%)$ pacientes e $\mathbf{S}$. epidermidis em $42(72,4 \%)$. Testes de sensibilidade as drogas foram realizados com todas as cepas de $\mathbf{S}$. aureus isoladas. $\mathbf{E}$ discutido o papel de portadores inaparentes desta bactéria nas cavidades oral e nasal, assim como alguns aspectos relacionados à sua transmissão e prevalência de piodermites entre populações indigenas.

\section{N T R O D U Ç Ã O}

A presença de Staphylococcus sp. nas cavidades naso-oro-faringeas, trato intestinal e pele de indivíduos sãos é comum, caracterizando o estado de portador inaparente.

Em populações indígenas, após o contato com a "civilização", alguns Autores têm verificado a ocorrência frequiente de piodermites que se manifestam com formas clínicas exuberantes e muitas vezes com caráter rebelde à antibioticoterapia (COIMBRA Jr. ${ }^{3}$; VIEIRA FILHO ${ }^{18}$ ).

No Brasil, o único trabalho do nosso conhecimento, que procurou estudar aspectos relativos a etiologia e a epidemiologia destas infecções entre populações indígenas, revelou a presença de diferentes cepas de Streptococcus sp., Staphylococcus aureus e Corynebacterium diphtheriae com agentes patógenos primários do processo infeccioso (LAWRENCE \& col. ${ }^{8)}$.

No presente artigo, continuamos a série de estudos que vem sendo realizada entre popu- lações indígenas do Estado de Rondônia, discutindo-se o papel epidemiológico dos portadores inaparentes de bactérias piogênicas na boca e nariz nos Suruí e nos Karitiana, assim como as formas de piodermites observadas nessas populações.

\section{MATERIAL E MÉTODOS}

O grupo indígena Suruí vive na Reserva do Posto Indígena 7 de Setembro, na área administrativa do Parque Indígena do Aripuanã. Quando do contato com a sociedade nacional, ocorrido em 1969, a população do grupo era estimada em 800 indivíduos. Em decorrência de epidemias de gripe, sarampo e tuberculose, verificadas logo após o contato, a população Suruí atual soma cerca de 300 indios, demonstrando as altas taxas de mortalidade do grupo. Maiores informações sobre a história do contato do grupo com a sociedade nacional são encontradas em PUTTKAMER ${ }^{15}$, DAVIS ${ }^{6}$ e COIMBRA Jr. ${ }^{3}$.

Trabalho realizado com apoio do Conselho Nacional de Desenvolvimento Científico e Tecnológico da Fundação Nacional do Indio

(1) Pesquisador do CNPq. Secretaria đa Saúde de Rondônia (78.900). Porto Velho - RO

(2) Núcleo de Medicina Tropical Universidade de Brasilia. Cx. Postal 15.2965 - (70.919), Brasilia - DF, Brasil 
COIMBRA JR., C. E. A.; SANTOS, R. V. \& TANUS, R, - Estudos epidemiológicos entre grupos indígenas de Rondônia. I - Piodermites e portadores inaparentes de Staphylococcus sp. na boca e nariz entre os Suruí e Karitiana. Rev. Inst, Med. trop. São Paulo 27:13-19, 1985.

Os Karitiana habitam a Reserva do Posto Indígena Karitiana, às margens do igarapé Sapoti, afluente do Rio das Garças. Os primeiros contatos com a sociedade nacional datam do final do século passado, quando foram perseguidos por seringueiros. Segundo dados do CIMI ${ }^{2}$, a população atual é de 84 indivíduos. Informações referentes ao histórico do contato do grupo pođem ser obtidas em LOPES ${ }^{9}$, METRAUX ${ }^{11}$ e HUGO ${ }^{7}$.

Para a pesquisa bacteriológica, coletamos o material em "swabs" de madeira com algodão umidecido em solução fisiológica, levados em tubos de ensaio estéries tapados com algodão para o laboratório do Núcleo de Medicina Tropical da Universidade de Brasília. Coletamos material das fossas nasais e de raspados da língua em indivíduos sem sintomas clínicos aparentes para a pesquisa de portadores sãos. $O$ trabalho de campo foi realizado durante o mês de julho de 1983, tanto na aldeia Suruí como na Karitiana.

No laboratório, os “swabs" eram imediatamente semeados em placas contendo ágarsangue e incubadas a $37^{\circ} \mathrm{C}$ por $24-48$ horas. Repicamos em caldo-tioglicolato, à mesma temperatura, as colônias isoladas suspeitas. Ao fim de 24 horas, preparávamos um esfregaço e, após coloração pelo Gram, os que apresentavam morfologia tipo Staphylococcus eram submetidos à prova de coagulase e fermentação da manita para sua confirmação. Utilizamos os meios de cultura de fabricação dos laboratórios Difco.

Realizamos antibiogramas com todas as cepas de $\mathbf{S}$. aureus isoladas, utilizando discos fabricados pelos laboratórios Cefar, à exceção da neomicina produzida pela BBL. Testamos apenas as drogas antimicrobianas distribuidas pela Central de Medicamentos (CEME), que são as usadas nas enfermarias da FUNAI: neo. micina (30 mcg), ampicilina $(10 \mathrm{mcg})$, estreptomicina $(10 \mathrm{mcg})$, penicilina $(10 \mathrm{mcg})$, tetraciclina $(30 \mathrm{mcg})$, gentamicina $(10 \mathrm{mcg})$, rifampicina (5mcg), sulfametoxazol+trimetropim (25mcg), eritromicina $(15 \mathrm{mcg})$, ácido nalidíxico $(30 \mathrm{mcg})$ e cloranfenicol ( $30 \mathrm{mcg}$ ).

Por motivo de ordem logística, não foi possivel realizarmos fagotipagem com as cepas de $\mathbf{S}$. aureus isoladas.

\section{TRATAIMENTO ESTATISTICO}

A prevalência de indivíduos portadores de S. aureus, segundo a fonte de isolamento (boca ou nariz), entre os grupos Karitiana e Suruí foi comparada estatisticamente pelo teste do "qui-quadrado", sendo analisada a possível associação entre a fonte de isolamento da bactéria e sua ocorrência nas populações indígenas em estudo. O mesmo foi realizado com S. epỉdermidis visando o mesmo objetivo.

\section{RESULTADOS}

Foram realizadas 191 culturas bacteriológicas a partir de material colhido na região bucal (lingua) e nasal (Tabelas I e II).

T A B E L A I

Prevalência de Staphylococeus aureus entre portadores inaparentes nos grupos indígenas Karitiana e Suruí, Rondônia, 1983

\begin{tabular}{ccc}
\hline Habitat & Grupo & Karitiana \\
\hline Língua & $16(27,6 \%)$ & $3(7,9 \%)$ \\
\hline Nariz & $5(8,6 \%)$ & $7(18,4 \%)$ \\
\hline Língua e nariz & - & - \\
\hline Negativos & $37(63,8 \%)$ & $28(73,7 \%)$ \\
\hline Total & $58(100 \%)$ & $38(100 \%)$ \\
\hline
\end{tabular}

T A B E L A II

Prevalência de Staphylococcus epidermidis entre portadores inaparentes nos grupos Karitiana e Suruí, Rondônia, 1983

\begin{tabular}{lcc}
\hline Habitat & Grupo & Karitiana \\
\hline Lingua & $17(29,3 \%)$ & $7(18,4 \%)$ \\
\hline Nariz & $14(24,1 \%)$ & $17(44,8 \%)$ \\
\hline Lingua e nariz & $11(19,0 \%)$ & $1(2,6 \%)$ \\
\hline Negativos & $16(27,6 \%)$ & $13(34,2 \%)$ \\
\hline Total & $58(100 \%)$ & $38(100 \%)$ \\
\hline
\end{tabular}

Entre os Suruí, dos 38 pacientes submetidos a exames bacteriológicos, foram isoladas cepas de $\mathbf{S}$. aureus em $10(26,3 \%)$ indivíduos, sendo $3(7,9 \%)$ a partir de material proveniente da boca e $7(18,4 \%)$ do nariz. Quanto ao $\mathbf{S}$. epidermidis, esta bactéria foi isolada $\mathrm{em}$ 7. (18,1\%) pacientes a partir da boca, em 17 $(44,8 \%)$ no nariz e em apenas um isolada si- 
COIMBRA JR;; C. E. A.; SANTOS, R. V. \& TANUS, R. - Estudos epidemiológicos entre grupos indígenas de Rondônia. I - Piodermites e portadores inaparentes de Staphylococcus sp. na boca e nariz entre os Suruf e Karitiana. Rev. Inst. Ned. trop. São Paulo 27:13-19, 1985.

multaneamente da boca e nariz. Em $13(34,2 \%)$ indivíduos as culturas foram negativas.

No grupo Karitiana, foram examinados 58 pacientes, isolando-se cepas de $\mathbf{S}$. aureus $\mathrm{em}$ $37(63,8 \%)$ indivíduos, sendo $16(27,6 \%)$ a partir da boca e $5(8,6 \%)$ do nariz. Em $16(27,6 \%)$ pacientes os exames foram negativos.

Não foram identificados portadores nasais e bucais, simultaneamente, de $\mathbf{S}$. aureus entre os Suruí, tampouco entre os Karitiana.

A análise da prevalência de indivíduos portadores de $\mathbf{S}$. aureus revelou a existência de associação significativa, ao nível de $5 \%$ de significância, entre as variáveis grupo indígena e fonte de isolamento da bactéria. Entre os Suruí, o S. aureus ioi isolado com maior frequiência no nariz (18,4\%) enquanto que entre os Karitiana, a frequiência de isolamento da bactéria foi maior na língua $(27,6 \%)$.
Também quanto ao $\mathbf{S}$. epidermidis conclui. se pela existência de associação entre grupo indígena e fonte de isolamento. A bactéria foi encontrada com maior frequiência, entre os $\mathrm{Su}$ ruí, também no nariz $(44,8 \%)$. Com os Karitiana, o maior número de isolamentos se deu na língua $(29,3 \%)$.

Os testes de sensibilidade aos agentes quimioterápicos realizados com as cepas de $\mathbf{S}$. aureus revelaram alto índice de resistência às drogas testadas (Tabela III). A droga que se apresentou com o maior indice de resistência bacteriana foi o ácido nalidíxico, com 28 $(93,3 \%)$ cepas resistentes, e $2(6,7 \%)$ pouco sensiveis. Apenas uma (3,3\%) cepa apresentou resistência à neomicina, enquanto que 17 $(56,7 \%)$ mostraram-se pouco sensíveis e 11 $(36,7 \%)$ sensíveis. Analisando a Tabela III, pode-se visualizar melhor o padrão de resistência às drogas antimicrobianas testadas.

T A B E I A III

Cepas de Staphylococcus aureus isoladas a partir de portadores sãos entre os grupos indígenas Suruí e Karitiana e seus padróes de sensibilidade frente a diferentes drogas antimicrobianas testadas

\begin{tabular}{|c|c|c|c|c|c|c|c|c|c|}
\hline \multirow[b]{2}{*}{$\begin{array}{l}\text { Drogas } \\
\text { testadas }\end{array}$} & \multicolumn{3}{|c|}{ Grupo Surui } & \multicolumn{3}{|c|}{ Grupo Karitiana } & \multirow[b]{2}{*}{$\begin{array}{l}\text { Total de } \\
\text { cepas } \\
\text { sensiveis }\end{array}$} & \multirow[b]{2}{*}{$\begin{array}{l}\text { Total de } \\
\text { cepas pouco } \\
\text { sensiveis }\end{array}$} & \multirow[b]{2}{*}{$\begin{array}{l}\text { Total de } \\
\text { cepas } \\
\text { resistências }\end{array}$} \\
\hline & $\begin{array}{c}\text { Cepas } \\
\text { sensíveis }\end{array}$ & $\begin{array}{c}\text { Cepas } \\
\text { pouco } \\
\text { sensíveis }\end{array}$ & $\begin{array}{l}\text { Cepas } \\
\text { resistentes }\end{array}$ & $\begin{array}{c}\text { Cepas } \\
\text { sensiveis }\end{array}$ & $\begin{array}{c}\text { Cepas } \\
\text { pouco } \\
\text { sensiveis }\end{array}$ & $\begin{array}{l}\text { Cepas } \\
\text { resistentes }\end{array}$ & & & \\
\hline Neomicina & 05 & 05 & - & 06 & 12 & 01 & $12(40,0 \%)$ & $17(56,7 \%)$ & $1(3,3 \%)$ \\
\hline Ampicilina & 06 & 01 & 03 & 02 & 10 & 07 & $9(30,0 \%)$ & $11(36,7 \%)$ & $10(67,7 \%)$ \\
\hline Estreptomicina & 06 & 04 & 一 & 06 & 11 & 02 & $13(43,3 \%)$ & $15(50,0 \%)$ & $2(6,7 \%)$ \\
\hline Penicilina & 05 & 01 & 04 & 01 & 07 & 11 & $17(23,3 \%)$ & $8(26,7 \%)$ & $15(50,0 \%)$ \\
\hline Tetraciclina & 05 & 02 & 03 & 06 & $\theta 6$ & 07 & $11(36,7 \%)$ & $18(60,0 \%)$ & $11(36,7 \%)$ \\
\hline Gentamicina & 09 & 01 & 一 & 10 & 06 & 03 & $20(67,7 \%)$ & $7(23,3 \%)$ & $3(10,0 \%)$ \\
\hline $\begin{array}{l}\text { Rifampicina } \\
\text { Sulfametoxazol }+\end{array}$ & 06 & - & 04 & 08 & 08 & 03 & $15(50,0 \%)$ & $8(26,7 \%)$ & $7(23,3 \%)$ \\
\hline Trimetropim & 07 & - & 03 & 08 & 02 & 09 & $14(46,7 \%)$ & $2(6,7 \%)$ & $13(43,3 \%)$ \\
\hline Eritromicina & 05 & 01 & 04 & 06 & 03 & 10 & $11(36,7 \%)$ & $4(3,3 \%)$ & $15(50,0 \%)$ \\
\hline Ácido Nalidíxico & - & 01 & 09 & - & 01 & 18 & - & $2(6,7 \%)$ & $28(93,3 \%)$ \\
\hline Cloranfenicol & 06 & 02 & 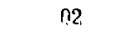 & 11 & 03 & 05 & $17(56,7 \%)$ & $5(16,7 \%)$ & $8(26,7 \%)$ \\
\hline
\end{tabular}

\section{DISCUSSÃO}

Os poucos trabalhos publicados sobre pio. dermites entre grupos tribais, como MARPLES 10 na Oceania, NSANZUMUHIRE \& col. $^{14}$ em Uganda e LAWRENCE \& col. ${ }^{8}$ no Brasil, têm constatado uma eleviada morbidade des tas infecções, associadas principalmente ao Staphylococcus aureus.

LAWRENCE \& col. ${ }^{8}$, ao estudarem a prevalência e etiologia de piodermites entre os grupos Ticuna e Kashinawa no Estado do Ama- zonas, registraram para o total da amostra exa minada (775), $11 \%$ de indivíduos com piodermites. Os Autores isolaram as seguintes bactérias a partir das lesões: Staphylococcus aureus, Streptococcus $\beta$-hemolítico grupo $A$ e $G$ e Corynebacterium diphtheriae.

COIMBRA Jr. ${ }^{3}$ relatou entre o grupo Suruí uma microepidemia de furunculose, observando-se na ocasião mais de 25 pacientes queixando-se de furúnculos, em apenas 20 dias. Esses furúnculos, denominados de "neg" pelos $\mathrm{Su}$ - 
COTMBRA JR., C. F. A.; SANTOS, R. V. \& TANUS, R, - Bstudos epidemioldgicos entre grupos indigenas de Rondönia. I - Plodermites e portadores inaparentes de Staphyloceccus sp. na boca e nariz entre os Surui $e$ Karitiana. Rev. Inst. Med. trop. Sâe Paulo 27:13-19, 1985.

rui, ocorriam com maior frequiência nos membros inferiores, nádegas, escroto, pálpebras $\mathrm{e}$ cabeça, podendo em alguns casos surgirem le- sões em diferentes locais do corpo simultaneamente (Fig. 1). Em todos os pacientes observados, os furunculos apresentavam.se de for-

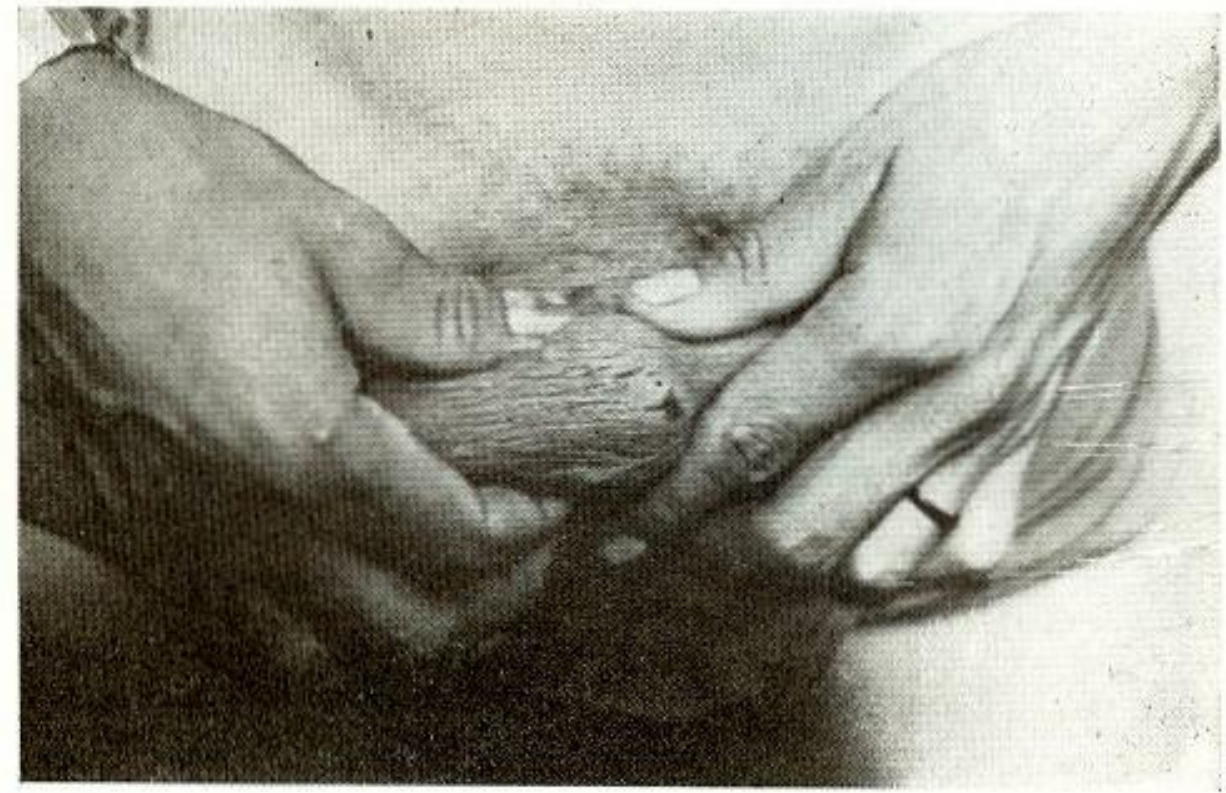

Fig. 1 - Furunculose no escroto e dedo na mão direita. Crupo Suruf, janeiro/1980

ma exuberance, entumescidos, vermelhos e muito doloridos até a drenagem do abscesso. O diâmetro variava de $0,5 \mathrm{~cm}$ (pálpebras) à $6 \mathrm{~cm}$ (na coxa) ou $8 \mathrm{~cm}$ (nas costas). Na cabeça, não ultrapassavam $3 \mathrm{~cm}$ de diâmetro, porém atingiam até $3,6 \mathrm{~cm}$ de altura. Ainđa entre os Suruí, COIMBRA Jr. \& MELLO' ${ }^{5}$ isolaram S. aureus de furúnculos em três pacientes observados, além de terem constatado diversos casos de impetigo, principalmente na cabeça, sem que tenha sido possivel isolar o agente responsável pela infecçẩo (Fig. 2).

Entre o grupo Karitiana, dois dos Autores (C.E.A.C.Jr, e R.V.S) estiveram na aldeia coletando material para pesquisa de portadores inaparentes de $\mathbf{S}$. aureus e nâo observaram nenhum caso de furunculose. Contudo, a enfermeira da FUNAI afirmou serem estas piodermites frequientes na população.

O fato é que a ocorrência destas piodermites entre populaçōes indigenas nåo se limita, pelo menos nas áreas que conhecemos, à uma simples infecçăo da derme. Frequentemente, ve. rificam-se complicaçōes secundárias, como os. teomielite.

Os indios referem-se a esta infecção como sendo "doenças de civilizado", já que afirmam que as desconheciam antes do contato com a nossa sociedade. Para tratarem das furunculo. ses e impetigo, os Suruí costumam emplastar a ảrea da lesăo com uma tintura espessa feita basicamente a partir das sementes de urucum (Bixa orelana), adictonada de óleo de babaçú (Orbignia martiana).

Para a compreensăo da epidemiologia das piodermites em grupos indigenas, alguns fatores concernentes à dinâmica de transmissăo dessas bactérias e em especial o $\mathbf{S}$. aureus, de. vem ser considerados, destacando-se o papel de portadores inaparentes de $\mathbf{S}$. aureus na manutenção da transmissăo da bactéria em sociedades fechadas como estas.

Como admitem WILLIAMS \& PATH ${ }^{19}$, o S. aureus 6 a única bactérla patogénica encontrada comumente sobre a pele, sendo o indice de portadores inaparentes sobre a pele să de 10 a $20 \%$. 
COMMBRA JR., C. E. A.; SANTOS, R. V. \& TANUS, R. - Estados epidemiologicos entre grupos indigenas de Ronđônia. I - Piodermites e portadores inaparentes de staphylococcus sp. na boca e nariz entre os Surui e Karitiana. Rev. Inst. Med. trop. Sĩo Paulo 27:13-19, 1985.

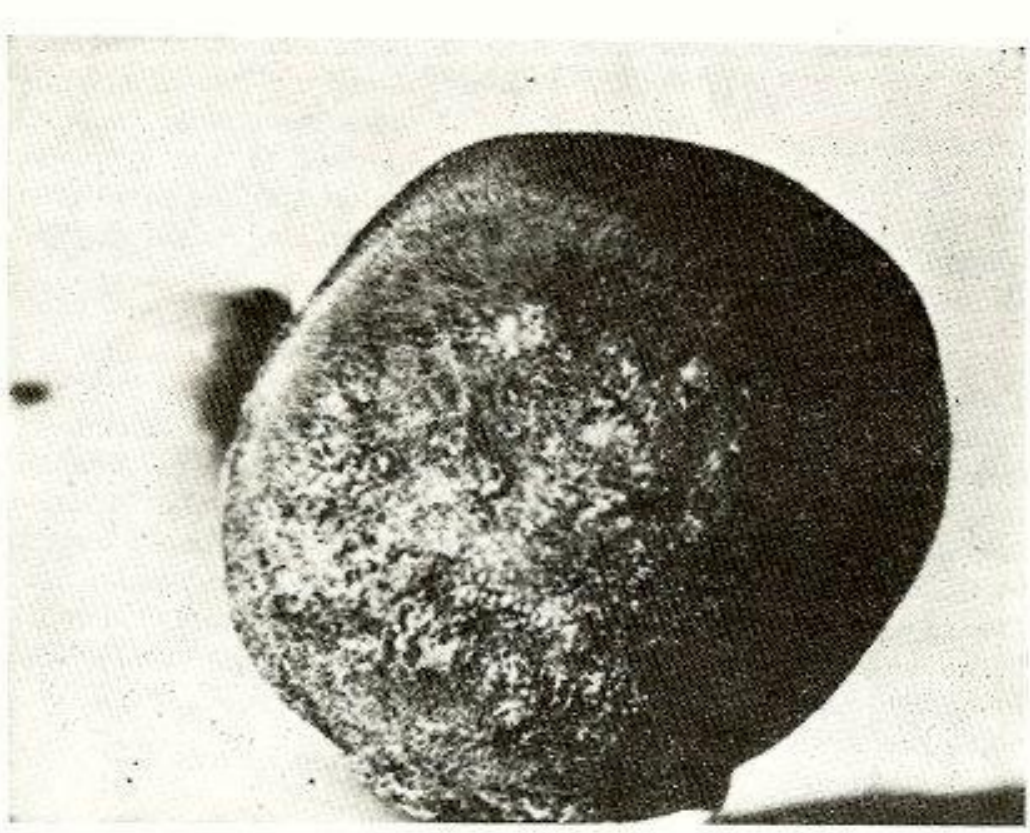

Fig. 2 - Impetigo na cabeça em um menino de aproximadamente 3 anos. Grupo Surui, julho/1980

Admite-se a existência de uma estreita associação entre portadores nasais de $\mathbf{S}$. aureus e a presença da bactéria na pele destes indivi. duos. WILLIAMS \& PATH ${ }^{19}$ observam que a ocorréncia de $\mathbf{S}$. aureus com mesmo padrăo fa. gotípico simultaneamente na pele e nariz de um indivíduo não é mera coincidência. A idéia de que o nariz é um habitat adequado para a sobrevivência de $\mathbf{S}$. aureus e de que sua ocorrência na pele estaria associada a sua presença no nariz é reforçada pelos trabalhos de MOSS \& col. ${ }^{13}$ e VARGAS \& WHITE ${ }^{17}$. Estes Autores, após suprimirem o estado de portador nasal através do uso de antibióticos tó. picos, verificaram acentuada reduçăo na freqüència de isolamento de $\mathbf{S}$. aureus da pele destes pacientes.

No presente trabalho, a prevalẻncia de portadores nasais e bucais de Staphylococcus sp. entre os Suruí e Karitiana foi diferente para os dois grupos. Enquanto para os Karitiana a cavidade bucal pareceu ser mais favorável como reservatório das bactérias (S. aureus; $27,6 \%$ na lingua para $86 \%$ no nariz; $\mathbf{S}$. epidermidis $29,3 \%$ na lingua para $24,1 \%$ no nariz), entre os Suruí a situaçăo se inverteu, tendo sido possível isolar maior número de bactérias a partir da cavidade nasal (S. aureus $18,4 \%$ no nariz para $7,9 \%$ na língua; S. epidermidis: $44,8 \%$ no nariz para $18,4 \%$ na lingua). Năo encontramos uma explicaçăo para este fato, no entanto, sob o ponto de vista epidemiológico, a importáncia do portador como fonte de infecção é a mesma quer apresente os estafilococos na boca quer apresente na fossa nasal, como demonstram os trabalhos recentes de ZELANTE \& col. 21,22 .

Nossa pesquísa revelou uma prevaléncia significativamente maior de portadores de $\mathbf{S}$. epidermidis em relação a $\mathbf{S}$. aureus. A primei. ra espécie, apesar de considerada na maioria das vezes como saprófita, pode, em alguns casos, assumir caráter patogènico, podendo determinar, entre outras infecçōes, piodermites e infecçōes urinárias, como já verificado por MITCHELL ${ }^{12}$; QUINN \& col. ${ }^{16}$; WISE ${ }^{20}$ e BAL. DY \& LOPES 1.

Quanto ás condições reinantes nas duas populaçóes estudadas e que podem estar relacionadas a transmissăo e manutenção de Staphylococcus sp. no meio ambiente, podemos apontar, além da presença de portadores nasais $\mathrm{e}$ orais das bactérias, os seguintes fatores: a) o uso contínuo de vestimentas sem lavá-las veri. ficado principalmente entre os Suruí e a troca de roupas entre si, o que facilita a disseminaçăo de estafilococos entre a população; b) a construçāo de casas nos moldes "civilizados" que, ao contrário das malocas tradicionais, apresentam teto muito baixo e insuficiente ventilaçāo, o que às tornam abafadas e úmidas. 
COIMBRA JR., C. E. A.; SANTOS, R. V. \& TANUS, R. - Estudos epidemiológicos entre grupos indígenas de Rondônia. I - Piodermites e portadores inaparentes de Staphylococcus sp. na boca e nariz entre os Suruí e Karitiana. Rev. Inst. Med. trop. São Paulo 27:13-19, 1985.

Agravado pelo fato de comportarem um número excessivo de pessoas.

Esses fatores favorecem a sobrevivência do estafilococos fora do organismo humano, podendo a bactéria permanecer, segundo BALDY \& LOPES ${ }^{1}$ em partículas de poeira, durante vários anos, persistindo viáveis, nos fomites, por tempo prolongado.

Os antibiogramas revelaram um alto índice de resistência aos agentes quimioterápicos usuais. Este problema jã foi aventado por COIMBRA Jr. \& MELLO $^{5}$ que, ao pesquisarem a etiologia de furunculose e impetigo entre o grupo suruí, também verificaram alto índice de resistência microbiana. A eficácia da antibioticoterapia pode ser diminuida devido a prescrição de antibióticos por indivíduos não quali. ficados nas enfermarias, acarretando pouco su. cesso nos tratamentos e gerando desconfiança pela população indígena em relação à medicina ocidental praticada entre o grupo.

O problema das piodermites entre popula ções indígenas deve merecer maior atenção por parte das agências governamentais ou missionárias responsáveis pela saúde destas populações. Essa observação é feita não só pela alta prevalência de piodermites e impetigo observada, mas também pelos prejuízos que estas in fecções ocasionam tanto ao indivíduo como à comunidade, ressaltando-se a incapacitação física temporária para o trabalho e complicações clínicas como esteomielites, podendo trazer graves sequielas para o indivíduo.

\section{SUMIMARY}

Epidemiological studies among amerindians of Rondônia. I - Pioderma and assymptomatic carriers of Staphylococcus sp. in the mouth and nose among the Suruí and Karitiana Indians

Bacteriological examinations were done with 38 Indian patients from the Suruí and 58 patients from the Karitiana groups, in the state of Rondônia, Brazil. Among the Suruí, S. aurexs was isolated in $10(26.3 \%)$ individuals and $\mathbf{S}$. epidermidis in $25(65,8 \%)$. In the Karitiana population, S. aureus was recorded from 21 $(36.2 \%)$ patients and $\mathrm{S}$. epidermidis from 42 $(72.4 \%)$. Sensibility tests to different drugs were done with all strains of $\mathbf{S}$. aureus isolated. The Authors discuss the role of assymptomatic carriers of these bacteria in the oral and nasal cavities, as well as some aspects related to its transmission and the prevalence of pyoderma infections within Indian population.

\section{AGRADECIMENTOS}

Ao Prof. Philip D. Marsden, do Núcleo de Medicina Tropical da Universidade de Brasilia, pelas sugestões emitidas. A Prof. ${ }^{a}$ Lucia Helena Chiarini, do Departamento de Estatística da Universidade de Brasília pela orientação dos cálculos. Ao Dr. Ari Miguel T. Ott da Secretaria da Saúde de Rondônia, pela revisão dos originais.

\section{REFERENCIAS BIBLIOGRAFICAS}

1. BALDY, J. L. S. \& LOPES, H. V. - Estafilococcias. In: Doenças Infecciosas e Parasitárias. $6 .^{2}$ eđ. (R. Veronesi, ed.). Rio de Janeiro, Guanabara Koogan, 1976

2. CIMI - População Indigena da Amazônia. PORANTIN (Conselho Indigenista Missionário), ano III n.० 23, out./1980.

3. COIMBRA Jr., C. E. A. - Relatório de Atividades de Pesquisas Desenvolvidas entre a Comunidade Suruí do P.I. 7 de Setembro. Fundação Nacional do Indio, Brasília, 1980a.

4. COIMBRA Jr., C. E. A. - Pahíter: Arte e Vida Suruí Edição Especial Cruzeiro do Sul Seguradora, Brasillia. Gráfica Só Brindes, 1980b.

5. COIMBRA Jr., C. E. A. \& MELLO, D. A. - Rela tório de Atividades de Pesquisas Desenvolvidas entre a Comunidade Suruí, Território Federal de Rondônia. Fundação Nacional do İnđio, Brasília, 1980.

6. DAVIS, S. H. - Victims of the Miracle, Cambridge, Cambridge University Press, 1977.

7. HUGO, V. - I Caritiana. Anthrops 56: 278-280, 1961.

8. LAWRENCE, D. N.; FACKLAM, R. R.; SOTTNEK, F. O.; HANCOCK, G. A.; NEEL, J. V. \& SALZANO, F. M. - Epidemiologic studies among ameridian popula tions of Amazonia. I. Pioderma: Prevalence and associated pathogens. Am. J. Trop. Med. Hyg. 28: 547-558, 1979.

9. LOPES, R. - Les Indiens Arikêmes. Proc. Inter. Con gress of Americanists XXI Gotborg 630-642, 1915.

10. MARPLES, M. J. - The incidence of certain skin diseases in Western Samoa: A preliminary survey. Trans. R. Soc. Trop. Med. Hyg. 44: 319-332, 1950. 
COIMBRA JR., C. E. A; SANTOS, R. V. \& TANUS, R. - Estudos epidemiológicos entre grupos indígenas de Ron. dônia. I - Piodermites e portadores inaparentes de Staphylococcus sp. na boca e nariz entre os Suruí e Karitiana. Rev. Inst. Med. trop. São Paulo 27:13-19, 1985.

11. MÉTRAUX, A. - The Tribes of Eastern Bolivia and the Madeira Headwaters. In: Handbook of Southamerican Indians (J. H. Steward, ed.). Smthosonian Institution, Bureau of American Ethonology, Washigton, D.C., 1948.

12. MITCHELL, R. G. - Staphylococci and urinary infection. Brit. Med. J. 1: 1127, 1965.

13. MOSS, B.; SQUIRE, J. R. \& TOPLEY, E. - Nose and skin carriage of Staphylococcus aureus in patients receiving penicillin. Lancet 1: 320-325, 1948.

14. NSANZUMUHIRE, R.; TAPLIN, D. \& LANDSDELL, L. - Pyoderma among Ugandan children. East Afr. Med. J. 49: 84-88, 1972.

15. PUTTKAMER, J, von - Brazil protects her Cintas Largas. National Geographie Magazine 140: 420-444, 1971.

16. QUINN, E. L. \& FISHER, M. - The problem of associating coagulase-negative Staphylococci with infection. Ann. N.Y. Acad. Sci. 128: 442, 1965 .

17. VARGAS, D. T. \& WHITE, A. - Suppresion of nasal, skin, and aerial Staphilococci by nasal application of methicillin. J. Clin. Invest. 40: 2209-2214, 1961.

18. VIEIRA FILHO, J. P. B. - Alguns aspectos das moléstias infecciosas e parasitárias posteriores ao contato com a civilização ocidental entre os inđios Xicrin e Gavião. In: Adaptação à Enfermidade e sua Distribuição entre Grupos Indígenas da Bacia Amazônica. Caderno CEPAM (Centro de Estudos e Pesquisas em Antropologia Médica), n.o 1, Brasilia (no prélo), 1983.

19. WILLIAMS, R. E. O. \& PATH, F. C. - Pathogenic Bacteria on the Skin. In: Skin Bacteria and their Role in Infection. (H.I. Maibach \& Hildick-Smith, eds.), New York, McGraw-Hill Book Co., 1965.

20. WISE, R. I. - Modern management of severe staphylococcal disease. Medicine 52: 295-304, 1973.

21. ZELANTE, F.; ASHGAR, H.; PIOCHI, B. J. A.; MONSON, C. A. \& CUNHA, P. S. - Staphylococcus aureus na boca e no nariz de indivíduos sãos. Verificação de identidade entre as cepas isoladas. Rev. Saúde Púb. São Paulo 16: 92-96, 1982.

22. ZELANTE, F.; ASFCAR, H.; PIOCHI, B. J. A. \& ALVES, M. P. - Observação sobre o padrão fágico de cepas Staphylococcus aureus isoladas da boca $e$ do nariz de indivíduos sãos. Rev. Saúde Púb. São Paulo 17: $123-129,1983$.

Recebido para publicação em $13 / 2 / 1984$. 